\title{
Role of RANKL-induced osteoclast formation and MMP-dependent matrix degradation in bone destruction by breast cancer metastasis
}

\author{
T Ohshiba', C Miyaura*,', M Inada' and A Ito' \\ 'Department of Biochemistry, School of Pharmacy, Tokyo University of Pharmacy and Life Science, 1432 Horinouchi, Hachioji, Tokyo 192-0392, Japan
}

Bone metastasis of breast cancer induces severe osteolysis with increased bone resorption. Osteoclast differentiation regulated by the receptor activator of NF- $\kappa$ B ligand (RANKL) in osteoblasts and matrix degradation induced by matrix metalloproteinases (MMPs) are thought to be involved in the process of bone resorption. When nude mice were inoculated with human breast cancer cells, MDA-MB-23I (MDA-23I), numerous osteoclasts resorbed bone and the degradation of the bone matrix markedly progressed in the femur and tibia with metastasis of the MDA-23I tumour. The expression of RANKL, MMP-I3 and membrane-type I-MMP mRNA was markedly elevated in bone with metastasis. When MDA-23I cells were cocultured with mouse calvaria, MDA-23I markedly induced bone resorption measured by calcium release from the calvaria, and the expression of RANKL, MMP-2 and MMP-I 3 was elevated in the calvaria after the coculture. The separation of MDA-23I from the calvaria using filter insert showed decreased bone resorption, suggesting that cell-to-cell interaction is essential for cancer-induced bone resorption. Adding MDA-23। cells to bone marrow cultures markedly induced osteoclast formation, and the expression of RANKL in osteoblasts was enhanced by contact with the cell surface of MDA-23I cells. These results indicate that RANKL-induced osteoclast formation and MMP-dependent matrix degradation are associated with osteolysis because of bone metastasis of breast cancer.

British Journal of Cancer (2003) 88, 13 I8-1326. doi:I0.1038/sj.bjc.6600858 www.bjcancer.com

(c) 2003 Cancer Research UK

Keywords: bone metastasis; bone resorption; osteoclast; matrix metalloproteinases; breast cancer

Bone is the most common site of metastasis in breast cancer. Tumour cells released from the primary focus infiltrate into the blood vessels and reach bone to form skeletal metastasis. Bone metastasis is accompanied by severe bone destruction, but the molecular mechanisms of the tumour-induced bone resorption are not fully understood. Previous studies have shown that bisphosphonate, an inhibitor of osteoclastic bone resorption, is a beneficial agent for the treatment of bone metastasis in patients with breast cancer (Hortobagyi et al, 1996). In an experimental metastasis model using human breast cancer cells, bisphosphonates such as ibandronate suppress bone metastasis by the promotion of apoptosis of osteoclasts (Hiraga et al, 2001). Using the same model, a neutralising antibody to parathyroid hormonerelated protein (PTHrP) suppresses bone metastasis (Guise et al, 1996). PTHrP is a secreted peptide produced by tumours and stimulates osteoclastic bone resorption (Powell et al, 1991). Although PTHrP is one of the candidates for regulators in tumour-induced osteolysis, other factors should also be involved in the mechanism of bone resorption at the site of metastasis.

Recently, the mechanisms of bone resorption have been actively examined, and the discovery of the receptor activator of NF- $\kappa \mathrm{B}$ ligand (RANKL) has allowed elucidation of the mechanism of osteoclast differentiation in bone (Anderson et al, 1997; Wong et al, 1997; Lacey et al, 1998; Yasuda et al, 1998). Osteoblasts and bone

*Correspondence: Dr C Miyaura; E-mail: chisato@ps.toyaku.ac.jp Received 16 September 2002; revised 13 December 2002; accepted 22 January 2003 marrow stromal cells express RANKL as a membrane-associated factor in response to bone-resorbing factors such as parathyroid hormone (PTH), interleukin-1 (IL-1) and prostaglandin E2 (PGE2). Osteoclast precursors possess RANK, a receptor for RANKL, and RANK - RANKL recognition induces the differentiation of the precursors into osteoclasts. In osteolysis associated with cancer metastasis, osteoclasts have to play an important role in the process of bone resorption. Recent studies have shown that OPG inhibits cancer-induced osteoclastogenesis and prevents tumour growth in bone (Morony et al, 2001; Zhang et al, 2001), suggesting that tumour cells use the RANKL: RANK axis to induce osteolysis.

Matrix metalloproteinase (MMP) is a family of proteolytic enzymes involved in the degradation of the extracellular matrix of various tissues including bone. More than 20 different mammalian MMPs have been identified, and divided into four subgroups; collagenase (MMP-1, MMP-8, MMP-13 and MMP-18), gelatinase (MMP-2 and MMP-9), stromelysin (MMP-3 and MMP-10) and membrane-type metalloproteinase (MMPs-14-17) (Mauviel, 1993; Nagase and Woessner, 1999; Vu and Werb, 2000). It is known that osteoblasts produce various MMPs such as MMP-1, MMP-2, MMP13 (collagenase 3) and MMP-14 (MT1-MMP), and that osteoclasts selectively produce MMP-9 (MacDougall and Matrisian, 1995; Kusano et al, 1998; Westermarck and Kahari, 1999). We have reported that the induction of MMPs (such as MMP-2, -3 and -13) in osteoblasts is essential for bone resorption (Kusano et al, 1998). On the other hand, the roles of MMPs in infiltration and metastasis of tumour cells have been widely investigated (MacDougall and Matrisian, 1995; Nakahara et al, 1997; Westermarck and Kahari, 1999). MT1-MMP expressed in tumour cells activates proMMP-2 
produced by stromal cells in the primary focus and at the metastatic site (Sato et al, 1994). Therefore, it is possible that MMPs are involved in the process of bone metastasis. However, the expression of MMPs in bone tissue with tumour metastasis and the roles of these enzymes produced by host cells in tumour-induced osteolysis have not been investigated as yet.

In this study, to clarify the role of RANKL-induced osteoclast formation and MMP-dependent matrix degradation in osteolysis because of bone metastasis, we examined the expression of RANKL and MMPs in bone with metastasis using the intracardiac injection of breast cancer cells. Expression of RANKL, MMP-2, MMP-13 and MT1-MMP was markedly elevated in bone with metastasis of breast cancer MDA-MB-231 cells in vivo. We established a new in vitro system for cancer-induced bone resorption using tumour cells cocultured with mouse calvaria, and found that cell-to-cell interaction between tumour cells and osteoblasts induced the expression of RANKL in osteoblasts, resulting in osteoclast formation. We suggest that RANKL-induced osteoclast formation and MMP-dependent matrix degradation are essential for osteolysis because of bone metastasis.

\section{MATERIALS AND METHODS}

\section{Animals, cells and reagents}

Female BALB/c nu/nu (nude) mice (5 weeks old), and $d d y$ mice, day 2, day 5 and 6 weeks of age were obtained from Japan SLC Inc. (Shizuoka, Japan). A human breast cancer cell line, MDA-MB-231 (MDA-231), was obtained from American Type Culture Collection (Rockville, MD, USA). MDA-231 cells were cultured in $\alpha$-modified MEM ( $\alpha$ MEM), supplemented with $10 \%$ fetal calf serum (FCS) at $37^{\circ} \mathrm{C}$ under $5 \% \mathrm{CO}_{2}$ in air. Recombinant human IL- $1 \alpha$ (IL-1) and recombinant mouse OPG were purchased from Genzyme/ TECHNE. BB94, a general inhibitor of MMPs, was kindly provided by British Biotech Pharm., Ltd (Oxford, UK).

\section{Intracardiac injections of MDA-231 in nude mice}

MDA-231 cells $\left(1 \times 10^{5}\right)$ were suspended in $0.1 \mathrm{ml}$ of PBS and injected into the left heart ventricle of 5-week-old female nude mice with a 27-gauge needle under anaesthesia with pentobarbital. Animals were kept in our specific pathogen-free animal facilities for 6 weeks. All procedures were performed in accordance with institutional guideline for animal research at the Tokyo University of Pharmacy and Life Science.

\section{Histological and radiographic analyses of the femur and tibia}

Radiographs of the femurs and tibiae were taken by soft X-ray (model CMB-2; SOFTEX, Tokyo, Japan). The femurs and tibiae were fixed with $70 \%$ ethanol and embedded in glycol methacrylate, and undecalcified $3-\mu \mathrm{m}$ sections were prepared and stained for tartrate-resistant acid phosphatase (TRAP) or haematoxylin-eosin (HE), as reported previously (Miyaura et al, 1997).

\section{Northern blot analysis}

Total RNA was extracted from the femur, tibia, cultured calvaria and cultured mouse osteoblastic cells, using the acid guanidiumphenol-chloroform method (Chen et al, 1997). For Northern blotting, $20 \mu \mathrm{g}$ of total RNA was resolved using electrophoresis on a $1 \%$ agarose-formaldehyde gel and transferred onto a nylon membrane (Hybond-N, Amersham Pharmacia Biotech, Tokyo, Japan), which was then hybridised with a ${ }^{32} \mathrm{P}$-labelled cDNA probe, as reported previously (Chen et al, 1997). A 946-bp fragment of mouse RANKL cDNA and a 485-bp fragment of mouse MMP-13 were prepared using $\mathrm{RT}-\mathrm{PCR}$ cloning and used as the probes
(Kusano et al, 1998; Yasuda et al, 1998). Mouse MT1-MMP cDNA was kindly provided by Dr M Seiki, and a 656-bp fragment was used as the probe (Sato et al, 1994). The signals were densitometrically quantified using an NIH-image analyzer.

\section{RT - PCR analysis}

cDNA was synthesised from $5 \mu \mathrm{g}$ of total RNA by reverse transcriptase (Superscript II Preamplification System, Life Technologies, Grand Island, NY, USA) and amplified using PCR. The primers used in PCR for the mouse RANKL gene were $5^{\prime}$-GAC TCG ACT CTG GAG AGT- $3^{\prime}$ (sense primer) and $5^{\prime}$-GAG AAC TTG GGA TTT TGA TGC- $3^{\prime}$ (antisense primer). The reaction conditions for PCR were 32 cycles, denaturation at $94^{\circ} \mathrm{C}$ for $45 \mathrm{~s}$, annealing at $58^{\circ} \mathrm{C}$ for $45 \mathrm{~s}$ and extension at $72^{\circ} \mathrm{C}$ for $2 \mathrm{~min}$. The primers used in PCR for the mouse cathepsin K gene were $5^{\prime}$-CTT GTG GAC TGT GTG ACT- $3^{\prime}$ (sense primer) and 5' -AAC ACT GCA TGG TTC ACA$3^{\prime}$ (antisense primer). The reaction conditions for PCR were 25 cycles, denaturation at $94^{\circ} \mathrm{C}$ for $45 \mathrm{~s}$, annealing at $55^{\circ} \mathrm{C}$ for $45 \mathrm{~s}$ and extension at $72^{\circ} \mathrm{C}$ for $2 \mathrm{~min}$. The primers used in PCR for the mouse TRAP gene were $5^{\prime}$-TGA CAA GAG GTT CCA GGA-3' (sense primer) and 5'-AGC CAG GAC AGC TGA GTG-3' (antisense primer). The reaction conditions for PCR were 25 cycles, denaturation at $94^{\circ} \mathrm{C}$ for $45 \mathrm{~s}$, annealing at $55^{\circ} \mathrm{C}$ for $45 \mathrm{~s}$ and extension at $72^{\circ} \mathrm{C}$ for $2 \mathrm{~min}$. The primers used in PCR for the mouse glyceraldehyde-3-phosphate dehydrogenase (GAPDH) gene were $5^{\prime}$-TGA AGG TCG GTG TGA ACG GAT TTG GC-3' (sense primer) and 5'-CAT GTA GGC CAT GAG GTC CAC CAC-3' (antisense primer). The reaction conditions for PCR were 30 cycles, denaturation at $94^{\circ} \mathrm{C}$ for $45 \mathrm{~s}$, annealing at $60^{\circ} \mathrm{C}$ for $45 \mathrm{~s}$ and extension at $72^{\circ} \mathrm{C}$ for $2 \mathrm{~min}$. The PCR product was run on a $1.5 \%$ agarose gel and stained with ethidium bromide.

\section{Coculture of MDA-231 cells and mouse calvaria}

Ddy mice (5 days old) were killed and their calvariae were aseptically harvested and dissected free of suture tissues. The calvariae were divided into halves and cultured for $24 \mathrm{~h}$ in $0.5 \mathrm{ml}$ aMEM containing $1 \mathrm{mg} \mathrm{ml}^{-1}$ BSA. After preculture for $24 \mathrm{~h}$, each half calvaria was cocultured with MDA-231 cells $\left(1 \times 10^{5}\right)$ embedded in $21 \mu \mathrm{l}$ of type I collagen gel $\left(0.8 \mathrm{mg} \mathrm{m}^{-1}\right)$ for the positioning of coculture in 24-well plates. After 5 days of the coculture, the calvaria with MDA-231 cells was fixed with $10 \%$ formalin and used for histological analysis of TRAP and HE staining. To determine the bone-resorbing activity in the coculture, the concentration of calcium in the conditioned medium was measured on day 5 with a calcium kit (calcium C-test Wako; Wako Pure Chemical. Osaka, Japan). The conditioned medium was also used for Western blot analysis and gelatin zymography for the detection of MMP-2, MMP-9 and MMP-13. After the coculture, MDA-231 cells in collagen gel were removed from the calvaria, and the remaining calvariae were used for the extraction of total RNA for Northern blot analysis. In some experiments, the calvaria was separated from MDA-231 cells embedded in collagen gel using a cell culture insert with an $8.0 \mu \mathrm{m}$ pore (FALCON, Becton Dickinson, Franklin Lakes, NJ, USA).

\section{Gelatin zymography}

Gelatinase activity in the conditioned medium of the coculture of the calvaria and MDA-231 cells embedded in collagen gel was analysed by gelatin zymography (Kusano et al, 1998). Aliquots $(10 \mu \mathrm{l})$ were mixed with $5 \mu \mathrm{l}$ of nonreducing SDS-PAGE sample buffer, then subjected to SDS-PAGE using $10 \%$ polyacrylamide gels containing $0.6 \mathrm{mg} \mathrm{m}^{-1}$ of gelatin. After electrophoresis, the gels were incubated for $1 \mathrm{~h}$ in washing buffer consisting of $50 \mathrm{~mm}$ Tris- $\mathrm{HCl}$ containing $5 \mathrm{mM} \mathrm{CaCl}_{2}, 1 \mu \mathrm{M} \mathrm{ZnCl}_{2}$ and $2.5 \%$ Triton X100 to remove SDS, and then in the same buffer without Triton X- 
100 at $37^{\circ} \mathrm{C}$ for $1 \mathrm{~h}$. The gels were stained with $0.1 \%\left(\mathrm{wv}^{-1}\right)$ Coomassie Brilliant Blue in 50\% $\left(\mathrm{vv}^{-1}\right)$ methanol, $10 \%\left(\mathrm{vv}^{-1}\right)$ acetic acid, and destained in a solution of $30 \%\left(\mathrm{v} \mathrm{v}^{-1}\right)$ methanol and $1 \%\left(\mathrm{v} \mathrm{v}^{-1}\right)$ formic acid. Enzyme activity was detected as a clear zone in a darkly stained background.

\section{Western blot analysis}

An aliquot of the conditioned medium of the coculture of calvaria and MDA-231 cells embedded in collagen gel was subjected to SDS-PAGE using $10 \%$ polyacrylamide gels and the separated proteins were transferred to a polyvinylidene difluoride membrane (PVDF, Millipore, Tokyo, Japan). The membrane was first incubated for $18 \mathrm{~h}$ at $4{ }^{\circ} \mathrm{C}$ with $5 \%$ skim milk in phosphatebuffered saline containing $0.1 \%$ Tween-20 to block nonspecific binding, and then incubated for $2 \mathrm{~h}$ with polyclonal rabbit antimouse MMP-13 antibody, kindly donated by Dr G Murphy. After incubation with horseradish peroxidase-conjugated donkey antirabbit IgG for $1 \mathrm{~h}$, immunoreactive bands were detected with an ECL system (Amersham Pharmacia Biotech, Tokyo, Japan).

\section{Cultures of primary mouse osteoblastic cells and MDA-231 cells}

Primary osteoblastic cells were isolated from 2-day-old mouse calvariae after five routine sequential digestions with $0.1 \%$ collagenase (Wako, Tokyo, Japan) and $0.2 \%$ dispase (Godo Shusei, Tokyo, Japan), as described previously (Chen et al, 1997). Osteoblastic cells collected from fractions 3 to 5 were combined and cultured in $\alpha \mathrm{MEM}$ supplemented with $10 \%$ FCS at $37^{\circ} \mathrm{C}$ under $5 \% \mathrm{CO}_{2}$ in air. In some experiments, the MDA-231 cells were fixed with $3 \%$ paraformaldehyde and washed three times with culture medium. On the layer of fixed-MDA-231 cells, osteoblasts and/or bone marrow cells were cultured.

\section{Osteoclast formation in coculture of mouse bone marrow cells and osteoblasts}

Bone marrow cells $\left(2 \times 10^{6}\right.$ cells $)$ were isolated from 6 -week-old $d d y$ mice, and cocultured with the primary osteoblasts $\left(1 \times 10^{4}\right.$ cells) in $0.5 \mathrm{ml}$ of $\alpha \mathrm{MEM}$ containing $10 \%$ FCS in 24 -well plates. Primary osteoblastic cells were collected from newborn mouse calvariae as described above. To examine the effects of MDA-231 cells on osteoclast formation, MDA-231 cells $\left(1 \times 10^{4}\right.$ cells $)$ were added to the coculture system. The cultures were fed every 3 days by replacing $0.3 \mathrm{ml}$ of the old medium with fresh medium. Reagents such as OPG were added at the beginning of the culture and each time the medium was changed. After being cultured for 8 days, the cells adhering to the well surface were stained for TRAP. The TRAP-positive multinucleated cells containing three or more nuclei per cell were counted as osteoclasts.

\section{Statistical analysis}

The data are expressed as the means \pm s.e.m. The significance of differences was analysed using the Student's $t$-test.

\section{RESULTS}

\section{Osteolysis due to bone metastasis of breast cancer cells}

We first performed histological analyses in bone with metastasis of breast cancer cells, MDA-231 cells, using a typical in vivo model. Radiographic examination demonstrated the development of metastatic osteolytic lesions in the femur and tibiae 6 weeks after the injection of MDA-231 cells in nude mice (Figure 1). Tibiae were collected from these mice, and used for histological examination of the sections stained for HE and TRAP, a specific enzyme of
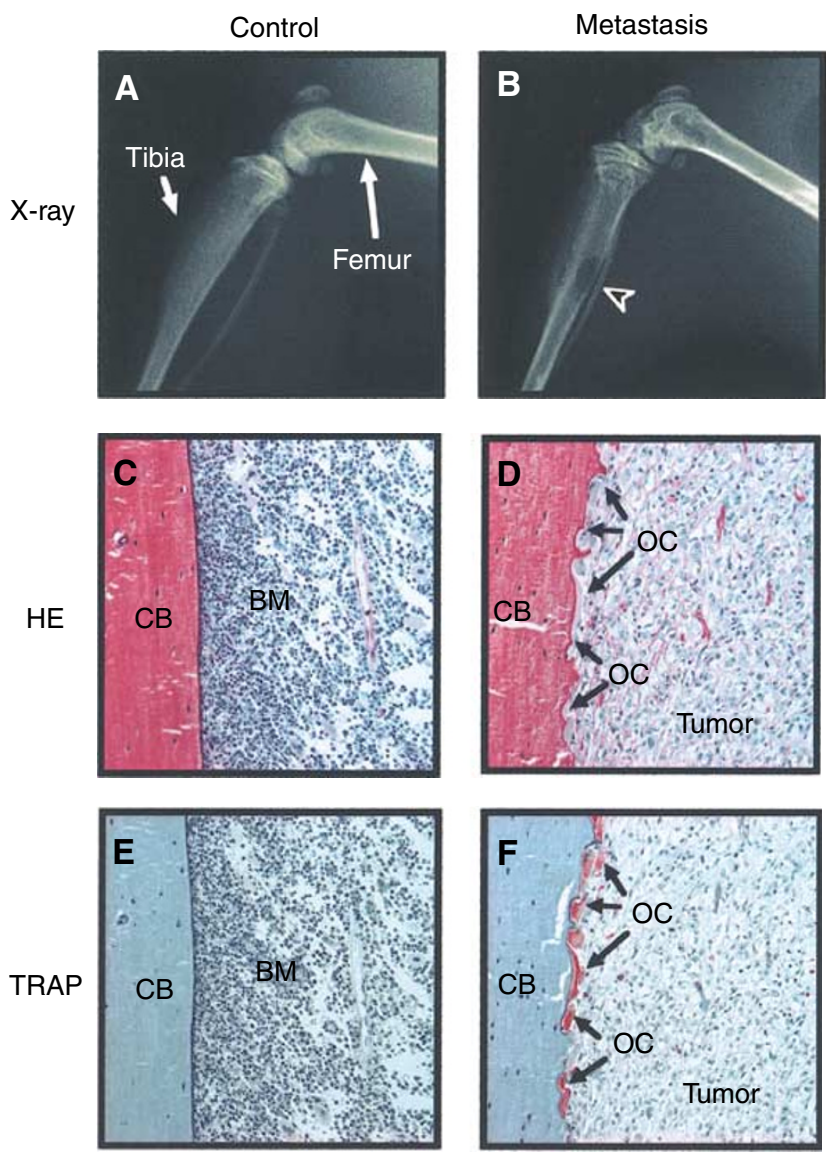

Figure I Representative radiographs and histological sections of osteolytic lesions in the hindlimbs of nude mice injected with MDA-23 I cells. (A, B) Soft X-ray analyses of the hindlimbs of control mouse injected with PBS (A) and mouse injected with MDA-23I cells (B). Arrowhead indicates the osteolytic lesion because of metastasis in the tibia. (C, D) HE staining of histological sections of tibia collected from the mice shown in panels $A$ and $B$, respectively. In the control section (C), bone marrow cells (BM) were normal and the cortical bone (CB) surface was smooth. In the metastasised section (D), tumour filled the bone marrow cavity and replaced the cellular elements. Arrows indicate osteoclasts $(\mathrm{OC})$ on the cortical surface. (E, F) TRAP staining of the serial sections of panels $C$ and $D$, respectively. In the metastasized section $(F)$, TRAP-positive osteoclasts were aligned on the cortical surface.

osteoclasts. Control tibia showed normal bone marrow cells and a smooth cortical bone surface. The sections of tibia with osteolysis indicated that metastatic tumour cells filled the bone marrow cavity and that a number of TRAP-positive osteoclasts aligned on the surface of the cortical bone and resorbed bone to form resorption pits (Figure 1). The TRAP-staining of MDA-231 cells was negative in the section of the metastatic region (Figure 1).

\section{Expression of RANKL and MMPs in bone with metastasis}

Using the model of bone metastasis of MDA-231 cells, we examined the expression of RANKL and MMPs in bone with metastasis. Figure $2 \mathrm{~A}$ shows the radiographic data of mice used in this experiment. Mouse A is control without injection of MDA-231 cells. Mouse B has severe osteolysis in the distal femur and slight osteolysis in the proximal tibia. Mouse C shows severe osteolysis in both the femur and tibia. From these mice, we collected the tibia and femur to extract total RNA and used for Northern blot and RT - PCR analyses to detect the mRNA expression of RANKL and MMPs. It is well known that cathepsin $\mathrm{K}$ and TRAP are specifically 
A

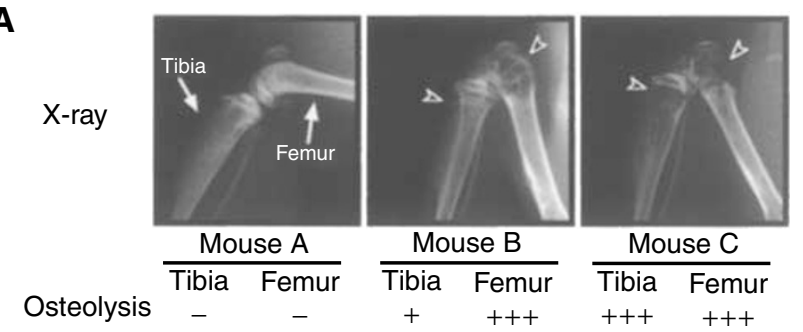

B

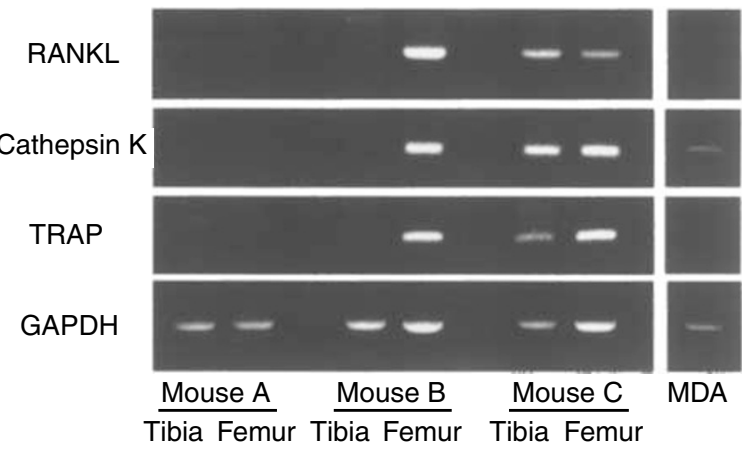

C

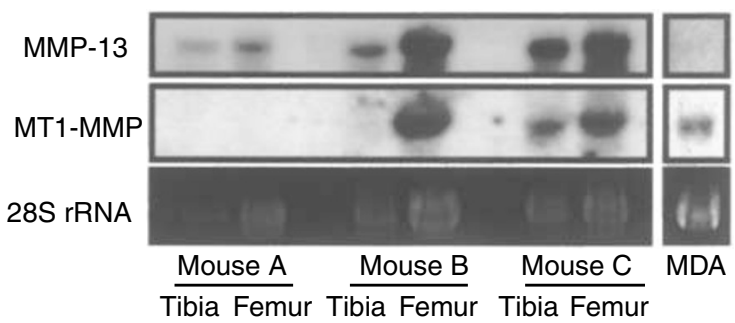

Figure 2 Expression of RANKL, cathepsin K, TRAP, MMP- I 3 and MTIMMP mRNA in bone with metastasis of MDA-23I breast cancer. (A) Nude mice were injected with or without MDA-23I cells and the hindlimbs were subjected to soft $X$-ray analyses. Arrowheads indicate the osteolytic lesions because of metastasis in the femur and tibia. Mouse $A$ is control mouse without injection of MDA-23I cells. Mouse B possesses slight metastasis in the tibia and severe metastasis in the femur. Mouse $C$ possesses severe metastasis in both the femur and tibia. (B) Total RNA was collected from the femur and tibia shown in panel $A$, and mRNA expression of RANKL, cathepsin $\mathrm{K}$ and TRAP was analysed by RT-PCR. (C) Expression of MMP-I3 and MTI-MMP mRNAs was analysed by Northern blotting using total RNA used in panel B. Note that marked expression of RANKL, cathepsin K, TRAP, MMP-I3 and MTI-MMP mRNAs was detected only in bone with severe osteolysis because of bone metastasis.

expressed in osteoclasts (Minkin, 1982; Saftig et al, 1998). The expression of cathepsin $\mathrm{K}$ and TRAP was markedly elevated in the femur of mouse B and in the femur and tibia of mouse C, indicating that osteoclastic bone resorption was in progress in these bones (Figure 2B). The expression of RANKL mRNA was hardly detected in bone without metastasis, but bone with severe metastasis exhibited a marked expression of RANKL mRNA. MMP-13 is a critical enzyme for the degradation of type I collagen, and is known to be produced by osteoblasts treated with boneresorbing factors (Kusano et al, 1998). The expression of MMP-13 mRNA was slightly detected in control bone in mouse A, and greatly elevated in bone with severe osteolysis in mice $\mathrm{B}$ and $\mathrm{C}$ (Figure 2C). MT1-MMP (MMP-14) is known to activate pro-MMP2 and pro-MMP-13, and is essential for bone remodelling (Sato et al, 1994; Knauper et al, 1996; Holmbeck et al, 1999; Zhou et al, 2000). The expression of MT1-MMP mRNA was hardly detected in bone without metastasis, but bone with severe osteolysis showed a marked expression of MT1-MMP (Figure 2C). In RT - PCR using human-specific primers for RANKL and MMP-13, we detected no expression of RANKL and MMP-13 mRNAs not only in MDA cells cultured in vitro but also in bone with severe metastasis (data not shown). This suggests that the expression of RANKL and MMPs detected in bone with severe osteolysis was mostly derived from bone in nude mice.

\section{Coculture of MDA-231 cells in collagen gel and mouse calvaria}

To examine the mechanism of tumour-induced bone resorption, we developed a new in vitro system using MDA-231 cells and calvaria collected from 5-day-old mice. MDA-231 cells were embedded in type I collagen gel to retain the position and cocultured for 5 days with mouse calvaria. Histological analysis showed that some MDA-231 cells in the collagen gel were in contact with the surface of the calvaria and that TRAP-positive osteoclasts formed resorption pits in the side of the calvaria attached to MDA-231 cells (Figure 3C, D). In calvaria treated with $2 \mathrm{ng} \mathrm{ml}^{-1}$ of IL-1, on the other hand, osteoclasts resorbed calcified bone on the inside of the calvaria (Figure 3E, F).

\section{Bone-resorbing activity and expression of RANKL and MMPs in coculture of MDA cells and mouse calvaria}

Using the coculture system of MDA-231 cells and mouse calvaria, we examined the bone-resorbing activity by measuring medium calcium. When calvarial tissues were cocultured for 5 days with MDA-231 cells, the bone-resorbing activity was markedly elevated and the level was similar to that induced by $2 \mathrm{ng} \mathrm{ml}^{-1}$ of IL-1 (Figure 4B). After the coculture, MDA-231 cells were removed from the calvarial tissues, and the expression of RANKL in the calvaria was examined by Northern blot analysis. In consistence with the data of bone-resorbing activity, the expression of RANKL mRNA was elevated in the calvaria cocultured with MDA-231 cells (Figure 4C). In this study, we also examined the expression of MMP-2, MMP-9 and MMP-13 by gelatin zymography and Western blot analysis. Gelatin zymography using the conditioned medium of the coculture revealed an enhanced production of pro-MMP-2, active-MMP-2 and pro-MMP-9. The production of MMP-13 was also elevated in the coculture with MDA-231 cells (Figure 4D). The level of MMP-2 and MMP-13 in the coculture was similar to that in the calvaria treated with $2 \mathrm{ng} \mathrm{ml}^{-1}$ of IL-1. In RT-PCR using human-specific primers for RANKL and MMP-13, the expression of their mRNAs could not be detected in both control MDA-231 cells and MDA-231 cells cocultured with calvaria (data not shown).

\section{Mechanisms of tumour-induced bone resorption}

To examine the role of RANKL and MMPs in bone resorption induced by MDA-231 cells, we added $100 \mathrm{ng} \mathrm{ml}^{-1}$ of OPG, a decoy receptor for RANKL, and $10 \mu \mathrm{M} \mathrm{BB94}$, a general inhibitor of MMPs, to the coculture of mouse calvaria and MDA-231 cells. The boneresorbing activity induced by MDA-231 cells was significantly suppressed by adding OPG and BB94 on day 5 (Figure 5B). Therefore, both RANKL and MMPs are involved in the mechanism of bone resorption induced by MDA-231 cells. Adding OPG and BB94 had little influence on the expression of RANKL mRNA in the coculture (Figure 5C). Adding OPG and BB94 showed no effect on growth of MDA-231 cells (data not shown).

Previous studies have shown the roles of soluble factors, such as PTHrP, produced by tumour cells in bone metastasis (Powell et al, 1991; Pederson et al, 1999). On the other hand, cell-to-cell interaction between tumour cells and stromal cells is thought to be essential for the production of cytokines and MMPs. To determine this point, the calvaria was separated from MDA-231 cells on day 5 in the coculture, as shown in Figure 5A. The bone-resorbing 

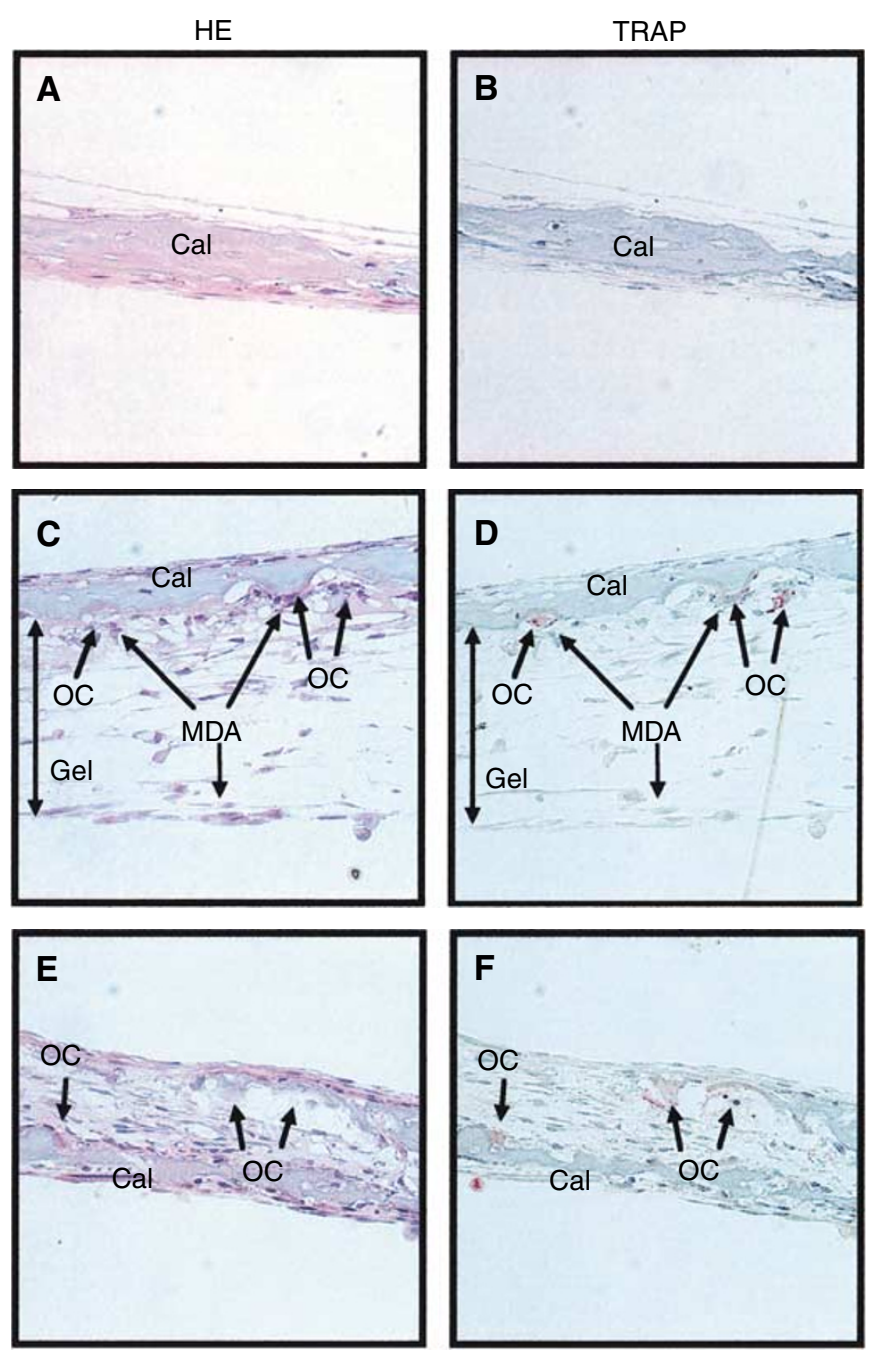

Figure 3 Histological view of coculture of mouse calvaria and MDA-23 breast cancer cells embedded in collagen gel. Calvariae were collected from 5-day-old mice, and cocultured for 5 days with MDA-23I cells, embedded in type I collagen gel to retain the position in culture plates. After the culture, the calvariae were fixed, sectioned and stained for HE and TRAP. (A, B) Section of the control calvaria. (C, D) Section of the coculture of calvaria and MDA-23I cells embedded in the gel. Osteoclasts and resorption pits were observed on the surface of the calvaria in contact with the gel containing MDA-23I cells. (E, F) As the positive control, calvariae were cultured for 5 days in the presence of $2 \mathrm{ng} \mathrm{ml}^{-1}$ of IL-I. Osteocalsts were observed inside the calvaria. Cal, calvaria; OC, osteoclasts; Gel, type I collagen gel; MDA, MDA-MD-23I.

activity induced by MDA-231 cells was significantly suppressed when the calvaria was separated from MDA-231 cells (Figure 5B). The level of expression of RANKL mRNA was reduced in a separate coculture, but the level was still higher than that in controls (Figure 5C). These results suggest that cell-to-cell and cellto-matrix interaction is essential for tumour-induced bone resorption, and that a soluble factor(s) produced by tumours is partially involved in the mechanism of bone resorption induced by breast cancer cells.

\section{Osteoclast formation induced by breast cancer cells in vitro}

In place of osteolysis because of bone metastasis, numerous osteoclasts appear on the surface of bone in vivo, as shown in
A

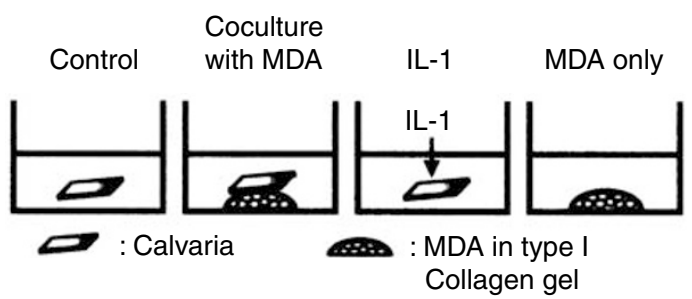

B

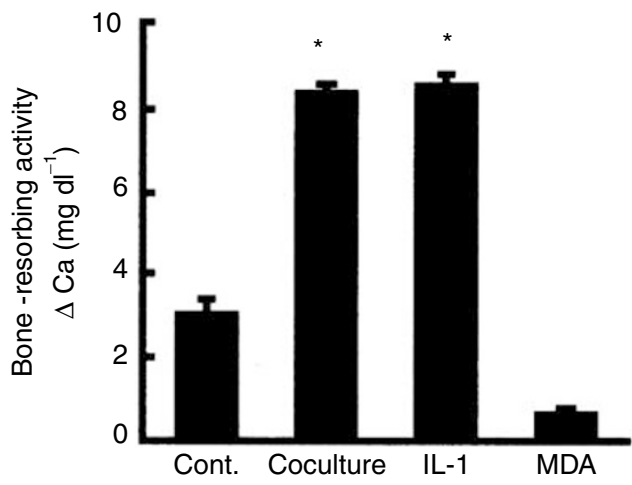

C
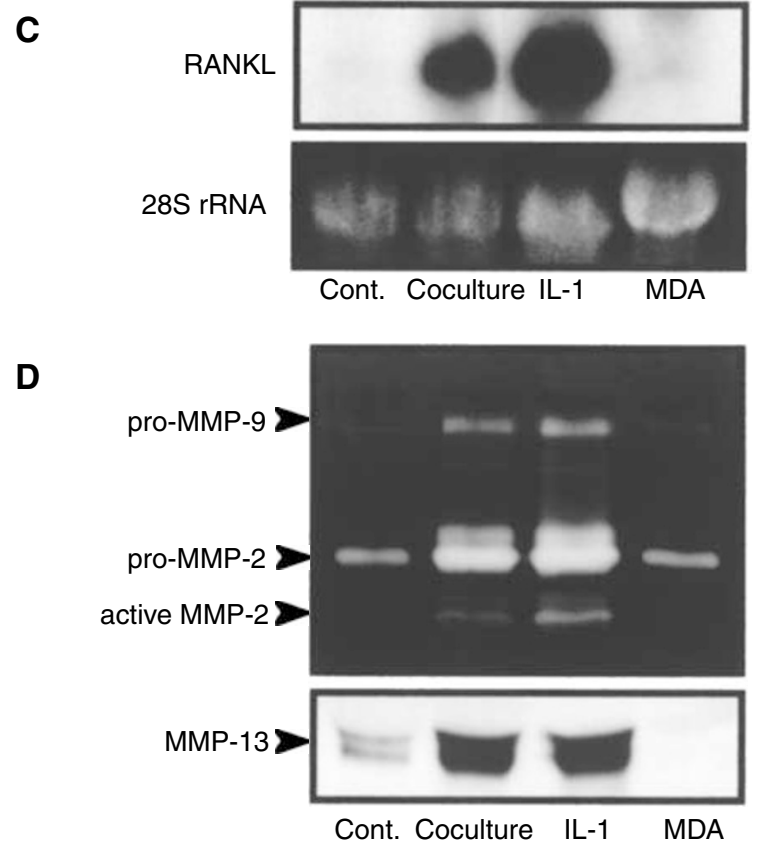

Figure 4 Bone-resorbing activity and expression of RANKL and MMPs in coculture of mouse calvaria and MDA-23I cells. (A) Illustrations of the experimental procedure of coculture of mouse calvaria and MDA-23I cells. Mouse calvariae were cocultured for 5 days with MDA-23I cells. As a positive control of bone resorption, calvariae were cultured for 5 days with $2 \mathrm{ng} \mathrm{ml} \mathrm{I}^{-1}$ of IL-I. MDA-23I cells $\left(\mathrm{I} \times 10^{5}\right.$ cells) were cultured for 5 days as MDA-23I control without calvaria. (B) Conditioned media were collected, and the concentration of calcium in the medium was measured to monitor the bone-resorbing activity. Data are expressed as means \pm s.e.m. of six cultures. Significantly different from the control $(* P<0.00 I)$. (C) Total RNA was extracted from calvaria-excluded MDA-23I cells, and Northern blotting was performed using ${ }^{32}$ P-labelled cDNA probes for RANKL as described in Materials and Methods. (D) Conditioned media were collected and gelatin zymography (upper panel) and Western blotting (lower panel) were performed as described in Materials and Methods. In the upper panel, gelatinase activities corresponding to pro-MMP-2, activeMMP-2 and pro-MMP-9 are indicated by arrows. In the lower panel, MMP13 was detected using anti-mouse MMP-I3 antibody. Note that the marked expression of RANKL, MMP-2 and MMP-I3 was detected in the calvaria cocultured with MDA-23I cells, and that the levels were similar to those indued by IL-I. 
A
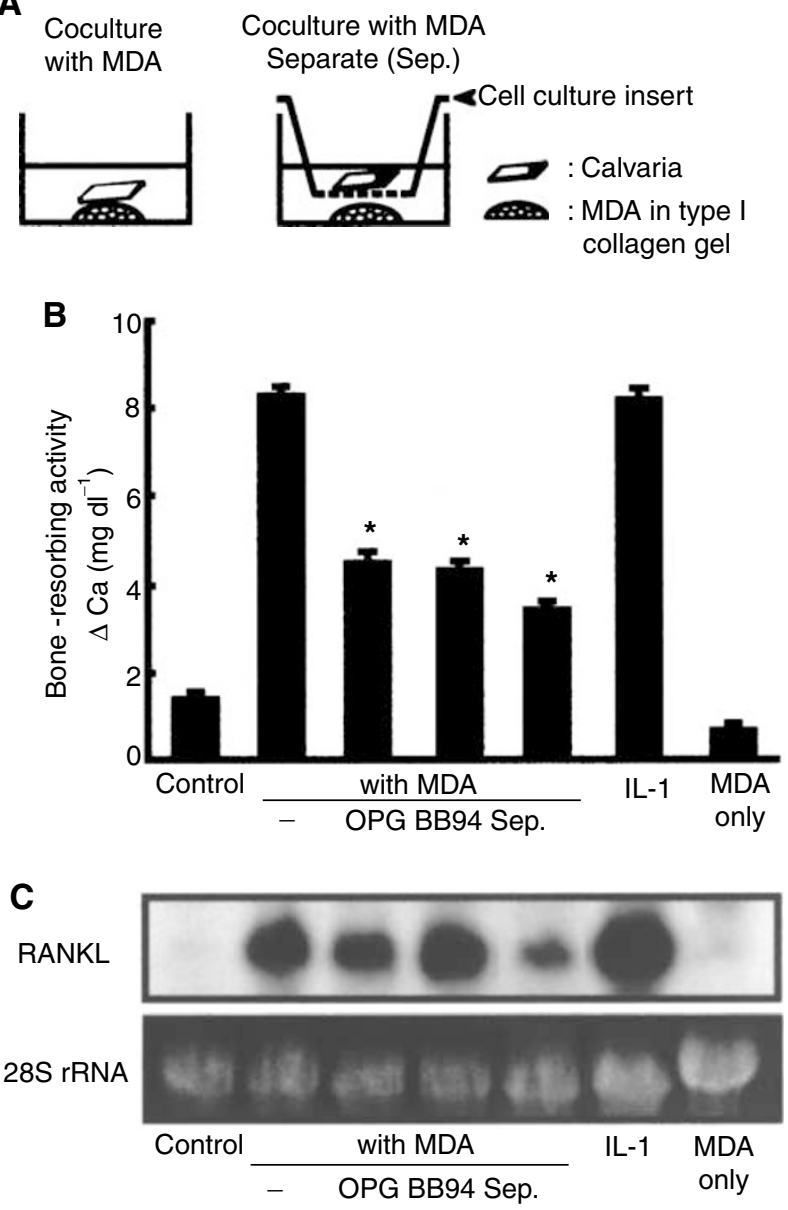

Figure 5 Roles of RANKL, MMPs and interaction between bone and tumour cells in bone-resorbing activity in coculture of calvariae and MDA231 cells. (A) Illustrations of the experimental procedure of coculture and separate coculture using 5-day-old mouse calvaria and MDA-23I cells embedded in collagen gel. In separate cocultures, calvariae were separated from MDA-23I cells using cell culture inserts, which permeate soluble factors present in the culture media. (B) Bone-resorbing activity was measured by the increase in medium calcium using conditioned media collected on day 5 from coculture and separate coculture shown in panel A. In the cocultures, a subgroup was added to osteoprotegerin (OPG: $100 \mathrm{ng} \mathrm{ml}^{-1}$ ) or BB94 $(10 \mu \mathrm{M})$. Some calvariae were cultured with $2 \mathrm{ng} \mathrm{ml}^{-1}$ of $\mathrm{LL}-\mathrm{I}$ as positive control of bone resorption. MDA-23। cells $\left(I \times 10^{5}\right.$ cells) were cultured on plate for 5 days as control without calvaria (MDA only). Data are expressed as means \pm s.e.m. of six cultures. Significantly different from the value of coculture with MDA-231 $(* P<0.00 \mathrm{I})$. (C) Total RNA was extracted from the calvaria used in the experiment shown in panel $\mathrm{B}$, and Northern blotting was performed using ${ }^{32} \mathrm{P}$-labelled cDNA probe for RANKL. In the cocultures, MDA-23I cells in the collagen gel were removed from the calvaria prior to the extraction of total RNA from the calvaria.

Figure 1. To test whether osteoclasts are formed by the presence of tumour cells in vitro, we added MDA-231 cells to the coculture of mouse bone marrow cells and osteoblasts. Usually, the addition of bone-resorbing factors is essential for osteoclast formation in the coculture system. However, as shown in Figure 6, adding MDA231 cells markedly induced osteoclast formation on day 8 without exogenous bone-resorbing factor. The osteoclast formation induced by MDA-231 cells was completely abolished by adding $100 \mathrm{ng} \mathrm{ml}^{-1}$ of OPG (Figure 6). In addition, when MDA-231 cells were separated from the bone marrow cells and osteoblasts using a cell culture insert, osteoclasts were not formed on day 8 in the
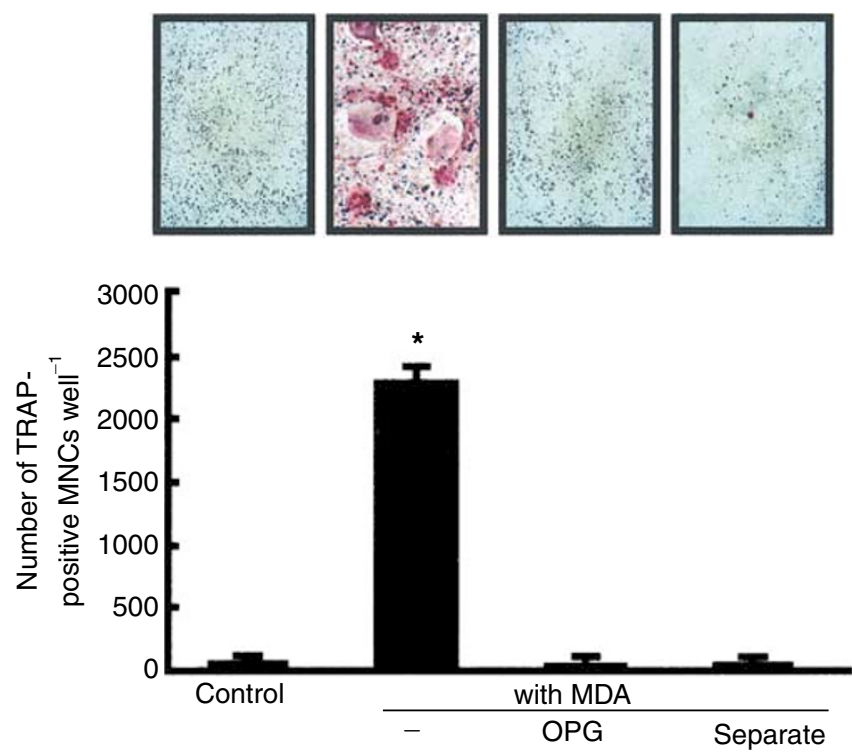

Figure 6 Osteoclast formation induced by MDA-23 I cells in cocultures of mouse bone marrow cells and osteoblasts. Mouse bone marrow cells $\left(2 \times 10^{6}\right)$ and osteoblasts $\left(1 \times 10^{4}\right)$ were cocultured for 8 days with MDA231 cells $\left(1 \times 10^{4}\right)$ in the presence or absence of $100 \mathrm{ng} \mathrm{ml}^{-1}$ of OPG. In a separate coculture, MDA-23I cells were separated from bone marrow cells and osteoblasts using a cell culture insert. (A) Representative field of TRAP staining. (B) The number of TRAP-positive multinucleated cells (MNCs) containing three or more nuclei was counted. Data are expressed as the means \pm s.e.m. of three wells. Significantly different from the control $(* P<0.001)$.

coculture. Therefore, cell-to-cell interaction is essential for MDA231-induced osteoclast formation.

\section{Adhesion to fixed MDA-231 cells induces the expression of RANKL in osteoblasts and osteoclast formation}

We next examined the effects of the adhesion of MDA-231 cells on the expression of RANKL mRNA in osteoblasts. MDA-231 cells were fixed with paraformaldehyde in the well, and mouse osteoblasts were added. At $3 \mathrm{~h}$ after adding the osteoblasts, the expression of RANKL mRNAs was elevated in the osteoblasts compared with the control osteoblasts without MDA-231 cells (Figure 7B). These results indicate that cell-to-cell contact between MDA-231 cells and osteoblasts induces the expression of RANKL on the surface of osteoblasts. Indeed, adding fixed MDA-231 cells could induce osteoclast formation on day 8 in a coculture of bone marrow cells and osteoblasts without any exogenous boneresorbing factor (Figure 7A).

\section{DISCUSSION}

The present study demonstrated that the expression of RANKL and MMPs including MMP-13 and MT1-MMP was markedly elevated in bone with metastasis in vivo, and that the levels of expression of RANKL and MMPs were correlated with the extent of osteolysis (Figure 2). To examine the mechanism of bone resorption induced by tumour cells, we established a new coculture system of mouse calvaria and MDA-231 cells embedded in collagen gel, and found that MDA-231 cells markedly induced the boneresorbing activity, the expression of RANKL in calvaria and the production of MMPs including MMP-2, MMP-9 and MMP-13 by calvaria (Figures 3 and 4). 
A

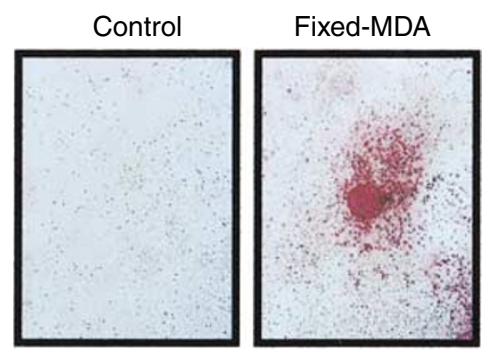

B

RANKL
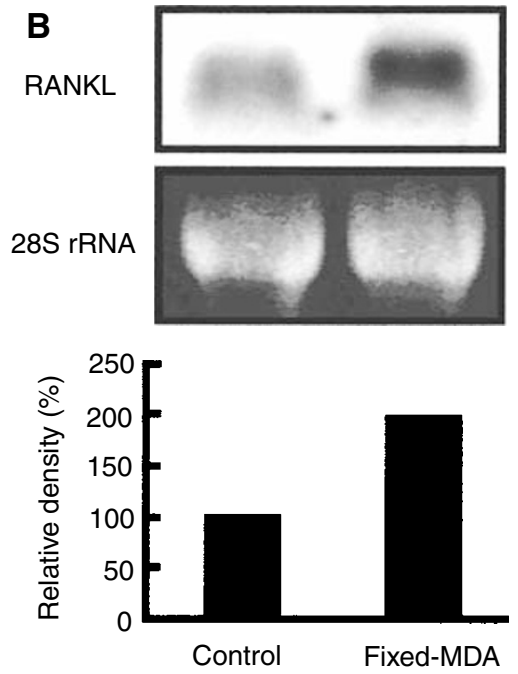

Figure 7 Cell-to-cell contact between osteoblasts and fixed-MDA-23 cells induces RANKL expression in osteoblasts, and osteoclast formation in coculture of bone marrow cells and osteoblasts. (A) Subconfluent MDA231 cells were fixed with paraformaldehyde and washed with culture medium. Mouse bone marrow cells and osteoblasts were cocultured for 8 days on the layer of fixed-MDA-23I cells. Red colour staining shows representative field of TRAP staining. (B) Mouse osteoblasts were added to a culture dish (control) or the layer of fixed-MDA-23I cells (fixedMDA), and cultured for $3 \mathrm{~h}$ to extract total RNA. Northern blotting was performed using ${ }^{32} \mathrm{P}$-labelled cDNA probe for RANKL. Signals in the upper panel were quantified using an image analyser as shown in the lower panel.

Recent studies have shown that RANKL expressed on the surface of osteoblasts is essential for osteoclast formation, and that osteoclast precursors, expressing RANK, recognise RANKL for their differentiation into mature osteoclasts (Anderson et al, 1997; Wong et al, 1997; Lacey et al, 1998; Yasuda et al, 1998). Adding MDA-231 cells to the coculture of mouse bone marrow cells and osteoblasts induced osteoclast formation without the requirement for any bone-resorbing factors (Figure 6). Using species-specific primers for RT-PCR, we distinguished the mRNA expression of human RANKL from that of mouse RANKL. MDA-231 cells showed no expression of human RANKL, whether bone cells were present or not (data not shown). Therefore, RANKL is expressed in host bone cells rather than MDA-231 cells. Zhang et al (2001) have reported that prostate cancer cells produce a soluble form of RANKL and directly induce osteoclastogenesis from osteoclast precursors. Although the tumour-induced osteoclastogenesis is mostly RANKL-dependent, the mechanism may be reliant on the tumour cells in each case.

OPG, an inhibitory molecule for osteoclastogenesis, binds to RANKL as a decoy receptor and suppresses the interaction between RANKL and RANK (Simonet et al, 1997; Tsuda et al, 1997; Kwon et al, 1998). Recent studies suggest that OPG may be a new therapeutic agent for bone loss associated with metabolic diseases such as osteoporosis and rheumatoid arthritis (Bucay et al,
1998; Kong et al, 1999; Kostenuik et al, 2001; Redlich et al, 2002). In the present study, OPG suppressed both bone resorption induced by MDA-231 cells in calvarial cultures and osteoclast formation induced by MDA-231 cells in bone marrow cultures. This is consistent with recent papers describing that tumour cells such as B16 melanoma and neuroblastoma induce osteoclast formation by a RANKL-dependent mechanism in vitro (Chikatsu et al, 2000; Michigami et al, 2001).

Bone resorption is mediated by not only osteoclast differentiation, but also matrix degradation. Cathepsin K and MMP-9 are selectively produced by osteoclasts in bone, but MMP-2, MMP-13 and MT1-MMP are mainly expressed in osteoblasts (Meikle et al, 1992; Reponen et al, 1994; Kinoh et al, 1996; Kusano et al, 1998). We have reported that bone-resorbing factors such as IL-1 and PGE2 markedly induced the expression of MMPs including MMP2, MMP-3 and MMP-13, and that the induction of MMPs was associated with an increase in bone-resorbing activity in mouse calvarial cultures (Kusano et al, 1998; Miyaura et al, 2000). Other reports have also shown that MMPs are involved in the process of bone resorption (Hill et al, 1994). In the present study, we detected a marked expression of MMP-13 and MT1-MMP in bone with metastasis in vivo (Figure 2). In coculture of mouse calvaria and MDA-231 cells, the production of MMP-2, MMP-9 and MMP-13 was markedly enhanced, and adding BB94, a general inhibitor of MMPs, significantly suppressed the bone-resorbing activity elicited by MDA-231 cells (Figures 4 and 5). Therefore, MMPs produced by osteoblasts and osteoclasts may contribute to the matrix degradation at the site of tumour-induced osteolysis.

MMPs are known to be involved in several processes of cancer metastasis. Infiltration of tumour cells from the blood vessels and invasion into metastatic organs are regulated by MMPs such as MMP-2 and MT1-MMP produced by host cells as well as tumour cells (MacDougall and Matrisian, 1995; Nakahara et al, 1997; Westermarck and Kahari, 1999). Yoneda et al (1997) have reported that osteolytic bone metastasis of breast cancer could be inhibited by combined treatment with bisphosphonate, a specific inhibitor of osteoclastic bone resorption, and tissue inhibitor of MMP (TIMP)-2, a natural inhibitor of MMPs. Since previous studies have shown that recombinant TIMP-1 and TIMP-2 inhibited bone resorption in vitro (Hill et al, 1993), TIMP-2 may suppress bone metastasis by inhibiting both tumour invasion and bone resorption.

Previous reports have shown that cancer cells produce various humoral factors such as PTHrP and bone-resorbing cytokines (Powell et al, 1991; Pederson et al, 1999). It is possible that a soluble factor(s) produced by tumour cells is involved in the mechanism of tumour-induced osteolysis. PTHrP was reported to contribute to breast cancer-mediated osteolysis (Powell et al, 1991), and anti-PTHrP neutralising antibody was shown to be effective in osteolysis (Guise et al, 1996). Mancino et al (2001) have reported that MDA-231 cells stimulate osteoclast formation by secreting macropahge colony-stimulating factor (M-CSF) and by enhancing the expression of RANKL in stromal support cells. It is well known that M-CSF produced by osteoblastic stromal cells is essential for osteoclast formation. In the present study, the boneresorbing activity induced by MDA-231 cells was significantly suppressed when the calvaria was separated from MDA-231 cells, but the activity was still higher than that of controls in calvarial cultures (Figure 5). Therefore, bone resorption induced by MDA231 cells may be due in part to humoral factors such as PTHrP and M-CSF produced by MDA-231 cells. On the other hand, cell-to-cell interaction seems to play an important role in osteoclast formation induced by MDA-231 cells, because osteoclast formation was completely suppressed when MDA-231 cells were separated from bone marrow cells (Figure 6).

To examine the role of cell-to-cell interaction between tumour cells and host cells in osteoclast formation, we fixed MDA-231 cells before the contact with bone marrow cells. Fixed MDA-231 cells 
induced osteoclast formation in bone marrow cultures and the expression of RANKL in mouse osteoblasts (Figure 7), indicating that molecule(s) expressed on the surface of MDA-231 cells may be recognised by osteoblasts. Osteoblasts as well as tumour cells express various integrins, and integrin signals are known to regulate osteoclast formation (Matsuura et al, 1996; Akatsu et al, 1998; Pommerenke et al, 2002). The molecules involved in cell-tocell recognition between MDA-231 cells and osteoblasts and the signal transduction for RANKL expression in osteoblasts are under investigation in our laboratory.

In conclusion, our present study demonstrated that the expression of RANKL and MMPs was markedly elevated in bone with osteolytic metastasis in vivo, and that breast cancer cells

\section{REFERENCES}

Akatsu T, Ono K, Murakami T, Katayama Y, Nishikawa M, Wada S, Yamamoto M, Kugai N, Matsuura N, Takada Y, Nagata N (1998) Chinese hamster ovary cells expression $\alpha 4 \beta 1$ integrin stimulate osteoclast formation in vitro. $J$ Bone Miner Res 13: 1251 - 1259

Anderson DM, Maraskovsky E, Billingsley WL, Dougall WC, Tometsko ME, Poux ER, Teepe MC, DuBose RF, Cosman D, Galibert L (1997) A homologue of the TNF receptor and its ligand enhance T-cell growth and dendritic-cell function. Nature 390: 175-179

Bucay N, Sarosi I, Dunstan CR, Morony S, Tarpley J, Capparelli C, Scully S, Tan HL, Xu W, Lacey DL, Boyle WJ, Simonet WS (1998) Osteoprotegerin-deficient mice develop early onset osteoporosis and arterial calcification. Genes Dev 12: $1260-1268$

Chen Q-R, Miyaura C, Higashi S, Murakami M, Kudo I, Saito S, Hiraide T, Shibasaki Y, Suda T (1997) Activation of cytosolic phospholipase A2 by platelet-derived growth factor is essential for cyclooxygenase-2-dependent prostaglandin E2 synthesis in mouse osteoblasts cultured with interleukin-1. J Biol Chem 272: $5952-5958$

Chikatsu N, Takeuchi Y, Tamura Y, Fukumoto S, Yano K, Tsuda E, Ogata E, Fujita T (2000) Interactions between cancer and bone marrow cells induce osteoclast differentiation factor expression and osteoclast-like cell formation in vitro. Biochem Biophys Res Commun 267: 632-637

Guise TA, Yin JJ, Taylor SD, Kumagai Y, Dallas M, Boyce BF, Yoneda T, Mundy GR (1996) Evidence for a causal role of parathyroid hormonerelated protein in the pathogenesis of human breast cancer-mediated osteolysis. J Clin Invest 98: 1544-1549

Hill PA, Murphy G, Docherty AJP, Hembry RM, Millican A, Reynolds JJ, Meikle MC (1994) The effects of selective inhibitors of matrix metalloproteinases (MMPs) on bone resorption and the identification of MMPs and TIMP-1 in isolated osteoclasts. J Cell Sci 107: $3055-3064$

Hill PA, Reynolds JJ, Meikle MC (1993) Inhibition of stimulated bone resorption in vitro by TIMP-1 and TIMP-2. Biochem Biophys Acta 1177: $71-74$

Hiraga T, Williams PJ, Mundy GR, Yoneda T (2001) The bisphosphonate ibandronate promotes apotosis in MDA-MB-231 human breast cancer cells in bone metastasis. Cancer Res 61: 4418-4424

Holmbeck K, Bianco P, Caterina J, Yamada S, Kromer M, Kuznetsov SA, Mankani M, Robey PG, Poole AR, Pidoux I, Ward JM, Birkedal-Hansen H (1999) MT1-MMP-deficient mice develop dwarfism, osteopenia, arthritis, and connective tissue disease due to inadequate collagen turnover. Cell 99: 81 - 92

Hortobagyi GN, Theriault RL, Porter L, Blayney D, Lipton A, Sinoff C, Wheeler H, Simeone JF, Seaman J, Knight RD, Heffernan M, Reitsma D (1996) Efficacy of pamidronate in reducing skeletal complications in patients with breast cancer and lytic bone metastasis. N Engl J Med 335: $1785-1791$

Kinoh H, Sato H, Tsunezuka Y, Takino T, Kawashima A, Okada Y, Seiki M (1996) MT-MMP, the cell surface activator of proMMP-2 (pro-gelatinase A), is expressed with its substrate in mouse tissue during embryogenesis. J Cell Sci 109: $953-959$

Knauper V, Will H, Lopez-Otin C, Smith B, Atkinson SJ, Stanton H, Hembry RM, Murphy G (1996) Cellular mechanisms for human procollagenase-3 (MMP-13) activation. J Biol Chem 271: 17124-17131

Kong YY, Feige U, Sarosi I, Bolon B, Tafuri A, Morony S, Capparelli C, Li J, Elliott R, McCabe S, Wong T, Campagnuolo G, Moran E, Bogoch ER, Van G, Nguyen LT, Ohashi PS, Lacey DL, Fish E, Boyle WJ, Penninger JM induced osteoclast formation by a mechanism involving cell-to-cell interaction between cancer cells and osteoblasts. Both RANKLinduced osteoclastogenesis and MMP-dependent matrix degradation may contribute to osteolysis because of bone metastasis.

\section{ACKNOWLEDGEMENTS}

We thank Dr G Murphy (University of Cambridge, UK) for her generous gift of anti-MMP-13 antibody, and Dr M Seiki (University of Tokyo, Japan) for his generous gift of mouse MT1-MMP cDNA.
(1999) Activated $\mathrm{T}$ cells regulate bone loss and joint destruction in adjuvant arthritis through osteoprotegerin ligand. Nature 402: 304-309 Kostenuik PJ, Capparelli C, Morony S, Adamu S, Shimamoto G, Shen V, Lacey DL, Dunstan CR (2001) OPG and PTH(1-34) have additive effects on bone density and mechanical strength in osteopenic ovariectomized rats. Endocrinology 142: 4295 - 4304

Kusano K, Miyaura C, Inada M, Tamura T, Ito A, Nagase H, Kamoi K, Suda $\mathrm{T}$ (1998) Regulation of matrix metalloproteinases (MMP-2, -3, -9, and 13) by interleukin-1 and interleukin- 6 in mouse calvaria: association of MMP induction with bone resorption. Endocrinology 139: $1338-1345$

Kwon BS, Wang S, Udagawa N, Haridas V, Lee ZH, Kim KK, Oh KO, Greene J, Li Y, Su J, Gentsz R, Aggarwal BB, Ni J (1998) TR1, a new member of the tumor necrosis factor receptor superfamily, induces fibroblast proliferation and inhibit osteoclastogenesis and bone resorption. FASEB J 12: $845-854$

Lacey DL, Timms E, Tan HL, Kelly MJ, Dunstan CR, Burgess T, Elliott R, Colombero A, Elliott G, Scully S, Hsu H, Sullivan J, Hawkins N, Davy E, Capparelli C, Eli A, Qian YX, Kaufman S, Sarosi I, Shalhoub V, Senaldi G, Guo J, Delaney J, Boyle WJ (1998) Osteoprotegerin ligand is a cytokine that regulates osteoclast differentiation and activation. Cell 93: 165-176

MacDougall JR, Matrisian LM (1995) Contributions of tumor and stromal matrix metalloproteinases to tumor progression, invasion and metastasis. Cancer Metast Rev 14: $351-362$

Mancino AT, Klimberg VS, Yamamoto M, Manolagas SC, Abe E (2001) Breast cancer increases osteoclastogenesis by secreting M-CSF and upregulating RANKL in stromal cells. J Surg Res 100: 18-24

Matsuura N, Puzon-McLaughlin W, Irie A, Morikawa Y, Kakudo K, Takada Y (1996) Induction of experimental bone metastasis in mice by transfection of integrin $\alpha 4 \beta 1$ into tumor cells. Am J Pathol 148: 55-61

Mauviel A (1993) Cytokine regulation of metalloproteinase gene expression. I Cell Biochem 53: 288-295

Meikle MC, Bord S, Hembry RM, Compston J, Croucher PI, Reynolds JJ (1992) Human osteoblasts in culture synthesize collagenase and other matrix metalloproteinases in response to osteotropic hormones and cytokines. J Cell Sci 103: $1093-1099$

Michigami T, Ihara-Watanabe M, Yamazaki M, Ozono K (2001) Receptor activator of nuclear factor $\kappa \mathrm{B}$ ligand (RANKL) is a key molecule of osteoclast formation for bone metastasis in a newly developed model of human neuroblastoma. Cancer Res 61: 1637-1644

Minkin C (1982) Bone acid phosphatase: tartrate-resistant acid phosphatase as a marker of osteoclast function. Calcif Tissue Int 34: 285-290

Miyaura C, Inada M, Suzawa T, Sugimoto Y, Ushikubi F, Ichikawa A, Narumiya S, Suda T (2000) Impaired bone resorption to prostaglandin E2 in prostaglandin E receptor EP4-knockout mice. J Biol Chem 275: $19819-19823$

Miyaura C, Onoe Y, Inada M, Maki K, Ikuta K, Ito M, Suda T (1997) Increased B-lymphopoiesis by interleukin 7 induces bone loss in mice with intact ovarian function: similarity to estrogen deficiency. Proc Natl Acad Sci USA 94: $9360-9365$

Morony S, Capparelli C, Sarosi I, Lacey DL, Dunstan CR, Kostenuik PJ (2001) Osteoprotegerin inhibits osteolysis and decreases skeletal tumor burden in syngeneic and nude mouse models of experimental bone metastasis. Cancer Res 61: $4432-4436$

Nagase H, Woessner JF (1999) Matrix metalloproteinases. J Biol Chem 274: $21491-21494$ 
Nakahara H, Howard L, Thompson EW, Sato H, Seiki M, Yeh Y, Chen W-T (1997) Transmembrane/cytoplasmic domain-mediated membrane type 1-matrix metalloprotease docking to invadopodia is required for cell invasion. Proc Natl Acad Sci USA 94: 7959-7964

Pederson L, Winding B, Foged NT, Spelsberg TC, Oursler MJ (1999) Identification of breast cancer cell line-derived paracrine factors that stimulate osteoclast activity. Cancer Res 59: 5849-5855

Pommerenke H, Schmidt C, Durr F, Nebe B, Luthen F, Muller P, Rychly J (2002) The mode of mechanical integrin stressing controls intracellular signaling in osteoblasts. J Bone Miner Res 17: 603-611

Powell GJ, Southby J, Danks JA, Stillwell RG, Hayman JA, Henderson MA, Bennett RC, Martin TJ (1991) Localization of parathyroid hormonerelated protein in breast cancer metastasis: increased incidence in bone compared with other site. Cancer Res 51: 3059-3061

Redlich K, Hayer S, Maier A, Dunstan CR, Tohidast-Akrad M, Lang S, Turk B, Pietschmann P, Woloszczuk W, Haralambous S, Kollias G, Steiner G, Smolen JS, Schett G (2002) Tumor necrosis factor alpha-mediated joint destruction is inhibited by targeting osteoclasts with osteoprotegerin. Arthritis Rheum 46: 785-792

Reponen P, Sahlberg C, Muhnaut C, Thesleff I, Tryggvason K (1994) High expression of $92-\mathrm{kDa}$ type IV collagenase (gelatinase $\mathrm{B}$ ) in the osteoclast lineage during mouse development. J Biol Chem 124: $1091-1102$

Saftig P, Hunziker E, Wehmeyer O, Jones S, Boyde A, Rommerskirch W, Moritz JD, Schu P, Figura K (1998) Impaired osteoclastic bone resorption leads to osteopetrosis in cathepsin-K-deficient mice. Proc Natl Acad Sci USA 95: $13453-13458$

Sato H, Takino T, Okada Y, Cao J, Shinagawa A, Yamamoto E, Seiki M (1994) A matrix metalloproteinase expressed on the surface of invasive tumor cells. Nature 370: $61-65$

Simonet WS, Lacey DL, Dunstan CR, Kelley M, Chang M-S, Luthy R, Nguyen HQ, Wooden S, Bennett L, Boone T, Shimamoto G, DeRose M, Elliott R, Colombero A, Tan H-L, Trail G, Sullivan J, Davy E, Bucay N, Renshaw-Gegg L, Hughes TM, Hill D, Pattison W, Campbell P, Sander S,
Van G, Tarpley J, Derby P, Lee R, Boyle WJ (1997) Osteoprotegerin: a novel secreted protein involved in the regulation of bone density. Cell 89: $309-319$

Tsuda E, Goto M, Mochizuki S, Yano K, Kobayashi F, Morinaga T, Higashio K (1997) Isolation of a novel cytokine from human fibroblasts that specifically inhibits osteoclastogenesis. Biochem Biophys Res Commun 234: $137-142$

Vu TH, Werb Z (2000) Matrix metalloproteinases: effectors of development and normal physiology. Genes Dev 14: $2123-2133$

Westermarck J, Kahari V-M (1999) Regulation of matrix metalloproteinase expression in tumor invasion. FASEB J 13: 781-792

Wong BR, Rho J, Arron J, Robinson E, Orlinick J, Chao M, Kalachikov S, Cayani E, Bartlett FS, Frankel III WN, Lee SY, Choi Y (1997) TRANCE is a novel ligand of the tumor necrosis factor receptor family that activates c-Jun N-terminal kinase in T cells. J Biol Chem 272: 25190-25194

Yasuda H, Shima N, Nakagawa N, Yamaguchi K, Kinosaki M, Mochizuki S, Tomoyasu A, Yano K, Goto M, Murakami A, Tsuda E, Morinaga T, Higashio N, Udagawa N, Takahashi N, Suda T (1998) Osteoclast differentiation factor is a ligand for osteoprotegerin/osteoclastogenesisinhibitory factor and is identical to TRANCE/RANKL. Proc Natl Acad Sci USA 95: $3597-3602$

Yoneda T, Sasaki A, Dunstan C, Williams P, Bauss F, Clerck YAD, Mundy GR (1997) Inhibition of osteolytic bone metastasis of breast cancer by combined treatment with the bisphosphonate ibandronate and tissue inhibitor of the matrix metalloproteinase-2. J Clin Invest 99: 2509-2517

Zhang J, Dai J, Qi Y, Lin D, Smith P, Strayhorn C, Mizokami A, Fu Z, Westman J, Keller ET (2001) Osteoprotegerin inhibits prostate cancerinduced osteoclastogenesis and prevents prostate tumor growth in the bone. J Clin Invest 107: 1235-1244

Zhou Z, Apte SS, Soininen R, Cao R, Baaklini GY, Rauser R, Wang J, Cao Y, Tryggvason K (2000) Impaired endochondral ossification and angiogenesis in mice deficient in membrane-type matrix metalloproteinase I. Proc Natl Acad Sci USA 97: 4052-4057 